\title{
Estrategias de mercadotecnia de la empresa familiar Café el Golfo, Guayabo Central, Siuna, 2013
}

\author{
Isabel del Socorro Masis Suazo ${ }^{1}$ \\ Thelma Arelis Centeno Lagos ${ }^{2}$ \\ Francisco Gutiérrez Garmendia ${ }^{3}$
}

\section{Resumen}

El estudio se realizó en la empresa Familiar Café El Golfo, ubicada en la comunidad Guayabo Central a 53 Kilómetros, sureste del Municipio de Siuna, Región Autónoma de la Costa Caribe Norte (RACCN). Se orientó al análisis de estrategias de mercadotecnia que utilizan, describe lo que implementa la microempresa, identificó las oportunidades de mercado en este negocio y propone acciones estratégicas con relación a los factores que influyen en este campo. Es de carácter descriptivo con un enfoque cualitativo. Las técnicas que se utilizaron fueron: la entrevista individual a propietarios de la microempresa, comerciantes y consumidores. La observación directa, se realizó en el área de producción y almacenamiento del producto. De acuerdo a la información que se obtuvo mediante la aplicación de los instrumentos en contraste con la teoría, se considera, que la microempresa Familiar Café El Golfo hace uso de estrategias de mercadotecnia, pero no en su totalidad.

Las propiedades físicas de este producto, prometen excelente oportunidades de mercado; sin embargo, es necesario que la empresa complemente otras estrategias de mercadotecnia a las que implementan por el negocio. Con respecto a las acciones estratégicas propuestas, estas servirán como una herramienta para el aumento de las ventas en la comercialización de su producto.

Palabras clave: Estrategias de mercado; comercialización de café; microempresa.

\section{Summary}

The research was conducted in the family business "Cafe El Golfo", located in the Guayabo Central community at 53 kilometers southeast of the municipality of Siuna, Autonomous Region of the North Caribbean Coast (RACCN). It was oriented to the analysis of the marketing strategies they employ; it also describes the actions implemented by the microenterprise, it identifies the market opportunities in this business and proposes strategic actions in relation to the factors influencing this field.

\footnotetext{
Lic. en Administración de Empresas con Mención en Banca y Finanzas. Docente de URACCAN. masisisabel@yahoo.com

Lic. en Administración de Empresas con Mención en Banca y Finanzas. Cajera en el Banco La FISE. tacl31@yahoo.com

Lic. en Administración de Empresas con Mención en Banca y Finanza. Docente de URACCAN.

franciscogutierrezgar@gmail.com
} 
The study is descriptive with a qualitative approach. The techniques that were used: individual interviews to owners of the microenterprise, traders and consumers. Direct observation was made in the production area and the storage of product. According to the information that was obtained by applying the instruments in contrast to the theory, it is considered that the family microenterprise "Cafe El Golfo" makes use of marketing strategies, but not entirely.

The physical properties of this product promises excellent market opportunities; however, the enterprise needs to complement other marketing strategies with those that they are actually implementing in the business. With regard to the strategic actions proposed, these will serve as a tool for increasing sales in marketing their product.

Keywords: Market strategies; coffee commercialization; microenterprise.

\section{Introducción}

La mercadotecnia es un proceso social y administrativo, mediante el cual grupos e individuos obtienen lo que desean, a través de generar, ofrecer e intercambiar productos de valor con sus semejantes (Kotler \& Armstrong, 2001, p.7).

El café es la segunda mercancía comercializada en el mundo después del petróleo. Se estima que 125 millones de personas viven del cultivo del café, incluyendo 25 millones de pequeños productores (Bedri, El café en el mundo, p.1). De la producción del café, no sólo depende un gran número de personas (25 millones en el mundo) sino también, muchos países productores, que a pesar de no ser uno de los principales países en la exportación de café al volumen mundial, su economía depende de un 80\% de su exportación (Bedri, El café en el mundo, p. 2).

En Centroamérica, el principal productor de café es Honduras, quien aporta el mayor porcentaje de café. En la economía del país obtuvo una participación del 25.1\% en el total de los Ingresos por Exportación de los Principales Productos Agrícolas. (Rodas, 2013). La producción del café en Nicaragua, es de importancia en la economía nacional y especialmente, en la economía campesina. Por lo que representa, un porcentaje elevado de empleo agrícola permanente y semipermanente, principalmente en las zonas rurales más pobres de la zona norte del país (Rodríguez, 2008,p.7). En la Región Autónoma de la Costa Caribe Norte (RACCN), sólo se cultiva el café en la Ciudad de Siuna y en el municipio de Waslala.

Actualmente, no existe un estudio que especifique las estrategias de mercadotecnia que implementan los pequeños productores de café del municipio de Siuna; no obstante es necesario que los productores agropecuarios, cuenten y manejen las mismas, lo que nos motivó a realizar el estudio que refleja: ¿Qué estrategias de mercadotecnia implementa la empresa familiar Café El Golfo? Identificar cuáles son las 
oportunidades de mercado que tiene la empresa, que permitan proponer acciones estratégicas que contribuyan a conquistar nuevos nichos de mercado.

El estudio, contribuye a que los productores de café, creen nuevas ideas de comercialización, mediante la implementación de mejores estrategias de mercadotecnia, en su unidad productiva, con el fin de maximizar los beneficios en la comercialización de los productos, por ende mejora de las condiciones socioeconómicas de las familias, involucradas en el rubro.

\section{Revisión de literatura}

\section{Generalidades}

Mercadotecnia: para (Pineda, s.f.) la mercadotecnia puede ser vista como un sistema global de actividades de negocios, que se proyectan para planear, establecer precio, promover y distribuir bienes y servicios que satisfacen las demandas de clientes actuales y potenciales. La mercadotecnia es en sí, un proceso social y administrativo por medio del cual los individuos y los grupos obtienen lo que necesitan y desean, mediante la creación y el intercambio de productos y valores con otros

Función de la mercadotecnia: el autor, Kotler y Armstrong, 1996, citan a (Pineda S/f.) quién opina, dentro de una organización, el área de mercadotecnia desempeña una función trascendental, porque a través de ella se cumplen algunos de los propósitos institucionales de la empresa. Su finalidad es la de reunir los factores y hechos que influyen en el mercado, para crear lo que el consumidor quiere, desea y necesita, lo distribuye de forma tal, que esté a su disposición en el momento oportuno, en el lugar preciso y al precio más adecuado

Estrategia de mercadotecnia: en el caso de (Martínez, 2009) indica, que una estrategia de mercadotecnia es, la forma en la que la organización de productores alcanza sus objetivos de mercadotecnia. No solo de ventas, lo cual es una confusión muy común, mercadotecnia no es exclusivamente ventas. La estrategia de mercadotecnia es un concepto más amplio y tiene que tener bien claro el mercado meta, es decir, a quién se quiere llegar, el posicionamiento que se busca, esto es, qué imagen se quiere dejar ante el mercado meta; la mezcla de mercadotecnia: las famosas $4 \mathrm{P}$ : precio, promoción, plaza y producto por último, los recursos que se necesitan para ejecutarla (p.1).

El producto: es un conjunto de atributos tangibles e intangibles que abarcan empaque, color, precio, calidad y marca, además del servicio y la reputación del vendedor; el producto puede ser un bien, un servicio, un lugar, una persona o una idea. En esencia, pues, los clientes compran mucho más que un conjunto de atributos 
cuando adquieren un producto: compran satisfacción en la forma de los beneficios que esperan recibir del producto (Stanton \& Etzel, 2007,p.221).

Para Kotler y Armstrong (1996) consideran que el precio, es la cantidad de dinero que se cobra por un producto o servicio. En termino más amplio del precio es la suma de los valores que los consumidores intercambian por el beneficio de poseer o usar el producto o servicio.

Mientras (Altamirano, 2010, p.18) refiere, que la plaza, también conocida como posición o punto, se entiende como las medidas que se deben tomar para que el mercado meta pueda acceder al producto o servicio que se comercializa.

Con relación a la promoción (Thompson, 2010) establece que la promoción es un elemento o herramienta de la mercadotecnia, que tiene como objetivos específicos, informar, persuadir y recordar al público objetivo acerca de los productos que la empresa u organización les ofrece, con lo que se pretende de esa manera, influir en sus actitudes y comportamientos, para lo cual, incluye un conjunto de herramientas como la publicidad, promoción de ventas, relaciones públicas, mercadotecnia directo y venta personal.

Las acciones estratégicas con relación a los factores de mercadotecnia para(Paladines, 2012, p.203)estas, se definen como las actividades realizadas para ejecutar la estrategia, decidida con anterioridad, para más tarde concretarlas, en programas detallados, denominado marketing-mix

Para poder diseñar las estrategias, en primer lugar se debe analizar el público objetivo, para luego, en base a dicho análisis, diseñar las estrategias para satisfacer necesidades o deseos, o aprovechar sus características o costumbres (Paladines, 2012, p.203).

Pero al diseñar estrategias de marketing, también tener en cuenta la competencia (por ejemplo, diseñar estrategias que aprovechen debilidades, o que se basen en las estrategias que les con buenos resultados), y otros factores tales como nuestra capacidad y nuestra inversión (Paladines, 2012, p.203).

\section{Materiales y métodos}

El presente estudio se realizó en la Comunidad "Guayabo Central" ubicado a $53 \mathrm{~km}$ al sureste del Municipio de Siuna, Región Autónoma del Costa Caribe Norte. Es de carácter descriptivo de enfoque cualitativo. Es descriptivo porque se explican las estrategias de mercadotecnia. La población seleccionada fueron 5 integrantes de la Familia, dueños de la Empresa, 3 clientes y 2 comerciantes que compran el café para comercializarlo, para un total de 10 personas. Las técnicas que se utilizaron fueron 
la entrevista y la observación directa en el área de producción y almacenamiento. Los descriptores involucrados: producto, precio, plaza, publicidad y promoción, personal, proceso y pro actividad en el servicio al cliente.

\section{Resultados y discusión}

Después de la aplicación de los instrumentos a los integrantes de la empresa familiar, Café El Golfo según los objetivos planteados se obtuvo:

\section{Estrategias de mercadotecnia}

En la empresa familiar "Café El Golfo", no se aplica un procedimiento de mercadotecnia según lo establecen los especialistas en la materia; sin embargo el dueño de la misma adquirió experiencia en el tema, al participar en talleres, capacitación y diplomado con temáticas de producción orgánica en café y cacao, impartidas por la certificadora Rainforest Alliance en Managua en el 2007. Otros talleres en los que se tuvo presencia fue en las impartidas por la Unión Nacional de Agricultores y Ganaderos UNAG - Siuna, y por la Asociación Coordinadora Indígena y Campesina de Agroforestería Comunitaria de Centroamérica (ACICAFOC).

El señor Roque Jacinto Centeno jefe de esta empresa familiar al respecto expresó que: ...ningún integrante de la micro empresa Café El Golfo, tiene conocimientos técnicos de mercadotecnia para comercializar el producto, sin embargo, estas actividades se realizan de acuerdo a los conocimientos trasmitido de familiares que han sido cafetaleros desde tiempos ancestrales y conocimientos adquiridos en talleres, capacitación y diplomados en el que han participado.

\section{Características del producto}

Café El Golfo, es un producto de consumo totalmente orgánico, producido y procesado por los propietarios de la empresa familiar de forma artesanal, el que se presenta al mercado con mayor auge en temporadas de cosechas y para abastecer el mercado local de Siuna, el resto del año, se almacena en pergamino, que posteriormente se procesa en pequeñas cantidades, determinado por la demanda de los consumidores.

La señora Petronila Leiva Centeno, integrante de esta empresa familiar expresó que:

El producto que comercializa la empresa familiar, es café molido, elaborado directamente del grano de café, y todo el proceso productivo es realizado de forma artesanal. 
Por otra parte, la mayoría de los consumidores de Café El Golfo que fueron entrevistados, coinciden en que el café, es un producto que satisface las necesidades de los clientes, al respecto expresan:

Café El Golfo, es un producto muy bueno en cuanto al sabor y aroma, en comparación con otros productos similares, al consumir este café se puede notar que es elaborado directamente del grano de café, sin ser adulterado.

Es un producto de alto rendimiento dado a su grado de pureza, al momento de consumirlo se puede disfrutar de su aroma y delicioso sabor.

Mediante la visita insitu, se confirma que la empresa familiar oferta al mercado un producto cien por ciento orgánico porque este es un producto elaborado directamente del grano de café, lo que garantiza su calidad, aroma y sabor.

\section{Calidad del producto}

Los entrevistados, expresaron que el control de la calidad, inicia desde el momento de la selección de la semilla, preparación del terreno, control de fertilización, y selección del follaje que se va a implementar, lo que garantiza que se obtenga un grano de café de muy buena calidad. La calidad del café molido, (valor agregado) que se le presenta al mercado depende del excedente secado que debe tener el grano de café, el cual oscila entre ocho y diez días de sol, hasta lograr un cero por ciento de humedad, para posteriormente proceder al tostado, que se realiza en un comal de barro, probándolo constantemente para darle el punto adecuado y que este no pierda su calidad durante el proceso.

El señor Roque Jacinto Centeno expresa que:

Para procesar el café en pergamino, tiene que tener cero por ciento de humedad, en donde para comprobar el nivel de humedad que tiene el grano de café se hace tacto con las manos, cuando este tiene cierto potencial de humedad no da la cáscara pero el que tiene o\% agua se aprieta y fácilmente da la cáscara.

Al respecto un cliente de la microempresa familiar expresa:

Café el Golfo es un producto de muy buena calidad, porque es cien por ciento café, solo que deberían mejorar, con respecto al grado de trituración del grano de café de modo que este no resulte muy fino ni muy grueso para que tenga un mayor rendimiento a la hora de su preparación.

El producto que comercializa la empresa familiar Café El Golfo, es de muy buena calidad, con relación a otros productos similares que se encuentran en el mercado; 
tomando en consideración que a pesar que es un producto que no ha sido elaborado de forma industrializada, conserva sus propiedades físicas, que lo caracterizan como un producto orgánico.

\section{El empaque}

La empresa familiar Café El Golfo, utiliza como empaque de su producto, bolsas plásticas transparentes, de alta calidad, con capacidad de contener una libra de café, elaborada por Termo Encogible. Sociedad Anónima de Capital Variable (S.A) de (C.V), estas bolsas no se rompen fácilmente a la hora de trasportar este producto, le permite a la empresa garantizar que el producto conserve sus propiedades físicas y llegue en buen estado hasta el consumidor final.

El Señor Roque Jacinto Centeno, propietario de la microempresa expresó que:

El empaque del producto que utiliza la empresa, son bolsa plásticas, elaboradas por Termo Encogible S.A de C.V, son bolsas resistente, que no se rompen fácilmente a la hora de trasportar el producto, Para el sellado de la bolsa se hace [...] con el apoyo de una sierra de segueta, pasando la bolsa plástica por una candela encendida, pero en un lugar donde entre poco aire, para evitar que exista una ruptura en la bolsa.

Con relación a lo anterior, los argumentos de los consumidores de Café EL Golfo, coinciden con las opiniones de los comerciantes de café cuando expresan que:

El café que comercializa esta empresa es un excelente producto, pero deben mejorar su empaque, para que le brinden más confianza al producto [...].

[...] los propietarios de Café El Golfo, deberían mejora el empaque del producto, y darle una mejor presentación, lo que permitirá que el producto tenga mayor demanda, ya que los consumidores no lo compran porque su empaque no brinda la confiabilidad necesaria para su consumo..."

En el estudio, se pudo apreciar que el empaque de Café El Golfo, no cumple las normas de registro y presentación de acuerdo a las normativas mercantiles y salubridad de Nicaragua, para que sea atractivo a la vista de los clientes y actualmente el producto solo se oferta en presentaciones de una libra, lo que dificulta su adquisición por todo los segmentos del mercado; esto afecta el nivel de venta del producto.

\section{Promoción}

Como estrategia de promoción, Café El Golfo, hace uso de dos herramientas de la mercadotecnia como: conceder descuentos por compras al por mayor, y obsequios 
de paquetitos de café, con el firme propósito de incentivar las ventas, esto permite que los clientes potenciales, prueben y conozcan el producto, interviniendo de esta forma en su decisión de compra.

Al respecto el señor Roque Jacinto Centeno, expresa que:

Para promocionar el producto, la empresa hace rebajas de cinco córdobas a los clientes que realicen compras al por mayor y se obsequian bolsitas de café de 203 onzas como prueba del producto, para aquellos clientes que no lo conocen.

Sin embargo, estos clientes potenciales no parecen percibir, la promoción y publicidad de este producto porque la mayoría expresan que desconocen su existencia.

Con relación a esto, los clientes afirman:

[...] no he tenido la oportunidad de comprar Café El Golfo, por la falta de conocimiento acerca de este producto, pero me gustaría consumirlo si existiera alguien que lo ofertara.

[...] es un excelente café, pero no se logra comprar en cualquier establecimiento [...].

lo he consumido por casualidad, porque una señora paso vendiendo, y decidí probarlo, porque me gusta consumir café de grano.

El estudio, revela que la empresa necesita fortalecerse el campo de promoción y publicidad de su negocio, debido a que no utilizan ningún medio de publicidad, para dar a conocer el producto, herramienta indispensable para lograr posesionarse en el mercado. En el municipio de Siuna, existen diferentes medios a través de los cuales las empresas realizan actividades publicitarias de sus negocios; aprovechar estos espacios, facilitaría a la empresa alcanzar sus objetivos en cuanto a ampliar su mercado meta.

\section{Oportunidades de mercado de Café El Golfo}

\section{Penetración de mercado}

Como una alternativa de penetración de mercado los propietarios de Café El Golfo realizan acciones de legalización de la empresa con el fin de contar con una marca registrada, que respalde la confiabilidad del producto y facilite la comercialización del café no solo el mercado local de Siuna, sino que también le abra las puertas a nuevos mercados en Rosita y Bonanza, a nivel regional y nacional 
Cabe destacar que el hecho de que Café El Golfo no cuenta con una marca registrada, se le ha hecho difícil posicionarse en el mercado.

El señor Roque Jacinto Centeno, manifiesta que:

[...] la empresa está luchando por obtener la patente a través de la marca BOSAWAS, por las limitantes a las que se enfrenta, al no contar un una identidad en el mercado, porque los centros de comercios, donde lo ofrecen, les solicitan presentar la certificación que demuestre la confiabilidad del producto, y aluden que, solo comercializan café de marcas reconocidas, porque es lo que demandan los clientes.

Según los comerciantes de café en el municipio de Siuna, es cultura de los clientes consumir café de marca reconocida.

$\mathrm{Al}$ respecto unos comerciantes expresaron:

No se pone en duda que sea un buen café, pero este no es muy confiable porque no tiene una marca que lo identifique en el mercado, lo que dificulta, una rápida comercialización.

En este establecimiento no se ha comercializado este producto, pero sería bueno hacer la prueba (...) aunque en principio quizás costará un poco venderlo debido a que los clientes están acostumbrados a consumir café de marca reconocida.

\section{Desarrollo de mercado}

Considerando que la empresa familiar Café El Golfo es una empresa joven, con características agropecuarias, pero con aspiraciones de incursionar en el ámbito comercial, esta se enfrenta a diversas limitantes que obstaculizan conquistar un espacio en el mercado.

Cabe destacar que además de lo pre escrito en el acápite anterior, el señor Roque Jacinto Centeno, refirió que Café El Golfo pretende desarrollar algunas herramientas de mercadotecnia, como el de mejorar el empaque, diseño de etiqueta, acciones que contribuirán a mejorar la presentación del café molido que actualmente oferta al mercado, con el fin de atraer nuevos clientes y ampliar el mercado objetivo.

La Universidad de las Regiones de la Costa Caribe Nicaragüense (URACCAN), es la única institución que ha ofrecido a la microempresa asesoramiento técnico y financiamiento económico, con el fin de impulsar el desarrollo de mercado de Café El Golfo. 
La señora Petronila Leiva Centeno destaca que:

Café El Golfo, cuentan con un financiamiento de la URACCAN, el cual se ha destinado para comprar equipos de procesamiento del café, con el fin fortalecer el desarrollo empresarial.

Mediante las pesquisas realizadas, se evidenció, la necesidad que tiene esta empresa de contar con una marca certificada, para poder penetrar en nuevos mercados, siendo esta la imagen de la empresa ante el público. De igual forma se identifica que la publicidad del producto por parte de la empresa es muy pobre, lo que contribuye a que sea vulnerable ante la competencia, por lo que urge, que la empresa promueva actividades de promoción y publicidad más agresiva dirigida a persuadir a los clientes actuales a consumir más el producto y a conquistar clientes de la competencia como un medio de penetración y desarrollo de mercado en aquellos segmentos que aún no se ha podido conquistar.

\section{Acciones estratégicas para lograr mejores oportunidades de mercado}

Las acciones estratégicas que se proponen a continuación, fueron elaboradas en base a las debilidades encontradas en el transcurso del estudio, así como también las opiniones y/o comentarios de algunos clientes fijos de Café El Golfo, la competencia que ofertan productos similares; sin dejar de considerar la capacidad de inversión de los propietarios de esta microempresa.

Entre las propuestas de acciones estratégicas que consideramos que deben implementar los propietarios de Café El Golfo, para establecer las bases estructurales y competir de manera exitosa en el futuro y lograr ventajas estratégicas están:

Estrategia con relación al producto:

1. Incluir un nuevo diseño al producto que contenga marca, nombre, logotipo del producto y algunas informaciones adicionales referente al producto.

2. Diversificar el tamaño del empaque, como una forma de fomentar las ventas e incidir en la decisión de compra de los consumidores.

Para esto, se debe comercializar el producto y utilizar el empaque propuesto en el acápite anterior, pero en varias presentaciones (bolsas de $25 \mathrm{~g}$, media libra y de una libra). Esto permitirá que las personas que no alcanzan comprar la libra de café,por razones económicas, pero necesitan el producto, puedan adquirirlo precio de menos costo por lo que la empresa no dejaría de vender el producto. 
3. Otra alternativa que se ajusta más a la capacidad de inversión de la empresa, es imprimir la etiqueta en forma de calcomanía y adherida al empaque que se utiliza actualmente para la comercialización de producto. Sin embargo lo más recomendable sería que se dé a imprimir el empaque en full color, porque la calcomanía puede ser fácilmente removida.

\section{Estrategia con relación a la promoción}

Las actividades que se detallan a continuación deben implementarse, como una estrategia de lanzamiento del producto, que facilitará que este sea más atractivo a los consumidores, interviniendo de esta manera en la decisión de compra.

1. Elaborar mantas publicitarias con mensajes que contengan información referente al producto y colocarlas en lugares de concurrencia pública, por ejemplo:

"Ya está en Siuna el café lo que todos estaban esperando, Café El Golfo cien por ciento Siuneño, con sabor al campo".

2. Por la compra de una libra de café, se regalar una bolsita de café de 5g; lo que permitirá que se incentive las ventas del producto.

3. A los intermediarios que logren distribuir más de cien libras de este café en el menor tiempo, se le regalan 10 libras adicionales a la venta que este realice.

4. Realizar anuncios publicitarios en radios y canales de televisivos, con el objetivo de que los clientes conozcan el producto y la dirección para adquirirlo.

La publicidad, constituye una herramienta mercadológica fundamental para dar a conocer un determinado producto al mercado meta; porque es la que se encarga de comunicar, persuadir y recordar al mercado meta, los beneficios y la disponibilidad del producto o servicio.

Los canales de comunicación en los que se puede pasar spot publicitarios están:

Radio URACCAN, Radio Siuna, Radio Saslaya, Radio Católica, entre otras; canales televisivos tales como: Siuna-Visión, Tele-Siuna y Canal 10 que es un canal con amplia cobertura a nivel nacional, e internacional, lo que facilitaría dar a conocer el producto al mercado. 


\section{Conclusiones}

Con base a los resultados y al análisis de la información que se obtuvo, se concluye:

Las estrategias de mercadotecnia que efectúa la empresa familiar Café El Golfo, se implementan de forma empírica; sin embargo, muchas de las decisiones que toman como: qué cantidad producir, qué empaque usar, el precio del producto, la promoción, el proceso y canales de distribución que se utilizan para hacer llegar el producto a los clientes, son parte de las estrategias de mercadotecnia.

Las oportunidades de mercado de esta microempresa, son favorables dentro del mercado competitivo, debido a que Café El Golfo es un producto cien por ciento orgánico. Por otra parte los propietarios de Café El Golfo, realizan gestiones de legalización de la empresa con el fin de contar con una marca registrada que les permita entrar a nuevos mercados.

Las acciones estratégicas propuestas en este estudio, están dirigidas a consolidar el éxito de la empresa; ya que estas permitirán incrementar las ventas y conquistar un espacio.

\section{Recomendaciones}

- Implementar nuevas estrategias, como las que propone el estudio.

- Legalizar la empresa.

- Mejorar en el cumplimiento las Normas de registro y presentación de acuerdo a las normativas mercantiles y salubridad de Nicaragua.

- Promocionar el producto por los diferentes medios de comunicación.

\section{Lista de referencias}

Altamirano. (2010). Mercadeo I: Comercialización de bienes y servicios.

Bedri. (s.f.). El café en el mundo. Bedri, 1.

Bedri. (s.f.). El café en el mundo. Bedri, 2.

Centro de Estudios para el Desarrollo Rural Sustentable y la Soberanía Alimentaria (CEDRSSA, 2013). Producción y mercado de café en el. Mexico.

Kotler, \& Armstrong. (2001). Marketing (Octava ed.). 
Martínez. (2009). Estrategia de Mercadotecnia. Recuperado el 1 de Febrero de 2013, de http://progresonetworko2o9.wordpress.com/2009/o3/13/definiendo-unaestrategia-de-mercadotecnia/mercadotecnia.html

Paladines. (2012). El proceso de mercadotecnia y la gestión de la comercialización de bienes $y$ servicios.

Pineda. (s.f.). Mercadotecnia. Recuperado el 15 de Enero de 2013, de http://www. usb.edu.mx/downloads/publicaciones/Gacetas_usb/Gaceta_u sb7/Gaceta1210Mercadotecnia.pdf

Stanton, \& Etzel. (2007). Fundamento de Marketing (Decimo cuarta ed.).

Thompson. (2010). La Promoción. Recuperado el 28 de Octubre de 2013, de http:// www.marketingintensivo.com/articulos-promocion/que-es-promocion.html 